\title{
1 Behavior of volatile compounds in membrane distillation: the case of carboxylic acids.
}

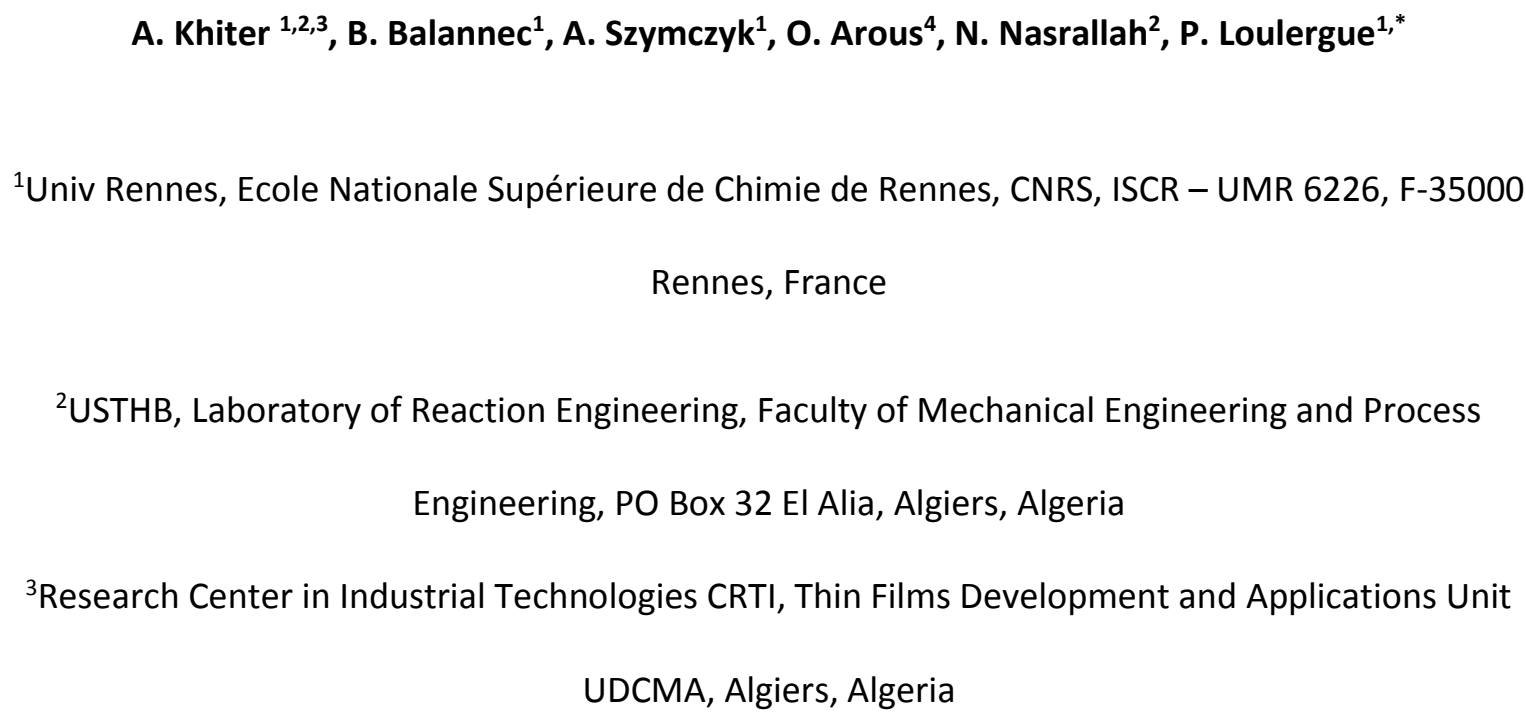

\section{Abstract}

Thanks to its unique features, membrane distillation (MD) has been particularly applied for desalination but also for niches applications with feed solutions containing a mixture of volatile molecules. For such solutions, the complex interplay of the solutes and solvent physicochemical and operating parameters makes it challenging to predict the separation efficiency by MD. There is thus a need for a better understanding of the behavior of volatile compounds in MD as well as the influence of their physicochemical environment. This study aimed at investigating the influence of different operating parameters on rejection efficiency of air-gap MD towards carboxylic acids (formic, acetic and succinic acids). Acid rejection was found to be highly dependent on the carboxylic acid structure. In addition, it increased with the acid concentration, which could be related to the formation of acid dimers in the feed solution. This behavior is opposite to what is classically observed for pressure-driven membrane processes thus suggesting that MD can be a suitable alternative to these techniques for the concentration/separation of carboxylic acids. On the other hand, acid rejection decreased with the 
increase of feed temperature which could be explained by the calculation of the apparent energies of activation of both the water and carboxylic acids using an Arrhenius-type model. Finally, the acid dissociation rate played a key role in the acid rejection. Taking advantage of this observation, it was demonstrated how a simple $\mathrm{pH}$ adjustment can be used to successfully achieve the selective separation of ethanol (compared to acetic acid) from an acetic acid/ethanol aqueous mixture (typical case of the extraction of bioethanol from a fermentation broth).

Keywords: Membrane Distillation; volatile molecules; carboxylic acids, selective separation

\section{Introduction:}

Membrane distillation (MD) is a thermal-based membrane operation allowing to separate molecules according to their volatilities. During the last decade, MD has gained considerable interest mainly because of its low electricity requirement as the separation apparent driving force (a temperature difference between the feed and permeate side of the membrane module) can be created using lowgrade energy sources including renewable energy [1,2] or waste heat [3-5].

Because of its relatively low sensitivity to polarization concentration compared to high pressure-driven membrane processes, MD has been particularly applied for seawater desalination as well as brine concentration including for full-scale application. Beside, niches applications have also been considered including, for example, wastewater treatment [6-8], fruit juice concentration [9-11], biomolecule extraction from fermentation broths [12-14] or nutrient recovery $[15,16]$.

From the separation point of view, considering the application of MD for desalination or for these niches applications, the issues strongly differ. Thus, desalination by MD is a relatively "simple" separation as the objective is to separate water (a volatile compound) from salts (nonvolatile compounds). For this application, the main challenges associated to the use of MD are thus the process stability (scaling, fouling and wetting issues) and the optimization of the overall energy consumption and process efficiency. Regarding the niches applications above-mentioned, the separation objectives 
might be different. Thus, if the feed fluid contains a mixture of different more or less volatile molecules, these challenges remain- but the question of the selectivity of the separation arises additionally. For example, in the case of the extraction of a biomolecule from a fermentation broth, one may want to extract solely the targeted molecule without any fermentation by-products. In the same way, during the treatment of petroleum wastewater, the unwanted transportation of volatile organic compounds through the membrane might impair the treated water quality. Thus, the existence of a mixture of volatile solutes into the MD feed solutions make the separation more complex than in the simple case of a feed containing only nonvolatile compounds in water. In this case, the solute concentration in the permeate can be increased or decreased compared to that of the feed solution $[14,17,18]$.

Achieving selective separations thus require a better understanding of volatile molecules behavior during MD. In previous studies, MD separation efficiency has been related to different physicochemical parameters of the solutes. MD being a liquid-vapor equilibrium based separation process, it is not surprising that the Henry's constant has been demonstrated to be a key parameter controlling the solute transport through the membrane $[17,19-21]$. However, other parameters such as molecular weight $[20]$ or solute hydrophobicity $[19,21]$ are also known to influence the separation efficiency. Accordingly, the most transferred compound is not always the most volatile one [21]. Besides the intrinsic properties of the molecules, other parameters related to the feed solution composition can also affect the separation efficiency such as the solute concentration $[14,22,23]$, the presence of ionic species (salting-out effect) $[14,24]$ or the $\mathrm{pH}[20,25]$ and its local variation due to concentration polarization [26]. Finally, operating parameters such as feed temperature, feed flow-rates and MD cell configuration for example are also known to play a role in the separation efficiency [27].

For solutions containing a mixture of volatile solutes, the complex interplay of these different parameters thus makes it challenging the prediction of the separation efficiency by MD. There is thus a need for a better understanding of the behavior of volatile compounds in MD as well as the influence of their physicochemical environment. 
8 1 2

In this context, this study aimed at investigating the behavior of different solutes of the same type according to the feed solution composition and the operating conditions. A set of three carboxylic acids (formic acid, acetic acid and succinic acid) was considered as they can be produced individually, or in mixture, by fermentation [28-31] and because acetic acid is present in mining wells and thus can be found in produced water [21] but as well in other types of wastewaters [18]. In this study, air-gap membrane distillation (AGMD) was considered because this configuration is the most widely used when dealing with (semi)industrial scale facilities [5]. The individual effects of the carboxylic acid structure, the concentration, $\mathrm{pH}$ and feed temperature on separation performances were studied. Finally, it was demonstrated how it can be taken advantage of the understanding of the behavior of acetic acid in MD to successfully achieve selective separation of ethanol from an acetic acid/ethanol aqueous mixture (typical separation in bioethanol production).

\section{Material and methods}

\subsection{Feed solutions}

Formic acid (purity $>98 \%$, Sigma-Aldrich, Germany), glacial acetic acid (VWR chemicals, France), succinic acid (> $99 \%$, Sigma-Aldrich, Germany), ethanol (96\% v/v, VWR chemicals, France) and deionized water (resistivity: $18 \mathrm{M} \Omega \mathrm{cm}$ ) were used to prepare the feed solutions.

Different carboxylic acid-water binary mixtures with acid concentrations in the range of $5-30$ g. $\mathrm{L}^{-1}$ were considered as well as a water - ethanol $\left(10 \mathrm{~g} \cdot \mathrm{L}^{-1}\right)$ - acetic acid $\left(2 \mathrm{~g} \cdot \mathrm{L}^{-1}\right)$ solution.

The main features of the molecules used in this study are gathered in table 1. 99 (1) 
Table 1: characteristics of the molecule used in this study

\begin{tabular}{|c|c|c|c|c|c|c|}
\hline & $\begin{array}{c}\text { Chemical } \\
\text { formula }\end{array}$ & $\begin{array}{c}\text { Molecular } \\
\text { weight } \\
\left(\mathrm{g} \cdot \mathrm{mol}^{-1}\right)\end{array}$ & LogP & $\begin{array}{c}\text { Vapor } \\
\text { pressure at } \\
25^{\circ} \mathrm{C}(\mathrm{kPa})\end{array}$ & $\begin{array}{c}\text { Boiling } \\
\text { temperature } \\
\left({ }^{\circ} \mathrm{C}\right)\end{array}$ & $\begin{array}{c}\text { pKa at } \\
25^{\circ} \mathrm{C}\end{array}$ \\
\hline Formic acid $^{\mathrm{a}}$ & $\mathrm{CH}_{2} \mathrm{O}_{2}$ & 46.0 & -0.54 & 5.7 & 101 & 3.75 \\
\hline Acetic acid & $\mathrm{C}_{2} \mathrm{H}_{4} \mathrm{O}_{2}$ & 60.1 & -0.17 & 2.1 & 118 & 4.75 \\
\hline Succinic acid & $\mathrm{C}_{4} \mathrm{H}_{6} \mathrm{O}_{4}$ & 118.1 & -0.59 & $0.1^{\mathrm{b}}$ & $\begin{array}{c}235 \\
\text { (decomposes) }\end{array}$ & $\begin{array}{c}4.21 \text { and } \\
5.64\end{array}$ \\
\hline Ethanol & $\mathrm{C}_{2} \mathrm{H}_{6} \mathrm{O}$ & 46.1 & -0.31 & 7.8 & 78 & 15.9 \\
\hline $\begin{array}{c}\text { Water (as } \\
\text { reference) }\end{array}$ & $\mathrm{H}_{2} \mathrm{O}$ & 18.0 & - & 3.1 & 100 & - \\
\hline
\end{tabular}

a Data obtained from [32-36] except the vapor pressure calculated by Antoine's law

${ }^{\text {b }}$ At $55^{\circ} \mathrm{C}$ (no data available at $25^{\circ} \mathrm{C}$ )

\subsection{AGMD set-up}

A commercial laboratory scale AGMD facility (XZero AB, Sweden) was used. It was equipped with a membrane cassette containing two flat-sheet membranes (total effective membrane area $0.195 \mathrm{~m}^{2}$ ). PTFE membranes with a pore size of $0.2 \mu \mathrm{m}$ and a polypropylene backing (Gore, USA) were used. According to manufacturer's data, these membranes had a thickness of $280 \mu \mathrm{m}$, a porosity of $80 \%$ while the liquid entry pressure was $238 \mathrm{kPa}$. The contact angle of the pristine membrane was $131 \pm 3^{\circ}$ (determined by the sessile drop method and using a GBX-DS apparatus equipped with a video acquisition system and the Windrop++ software). The air-gap thickness was set to $2 \mathrm{~mm}$ using polypropylene spacers. All experiments were performed using the same membrane cassette as no membrane fouling was observed. Pure water flux measurements were performed between experiments to check the membrane integrity and cleanliness.

AGMD experiments were performed by adjusting the feed temperature in the range $37-60^{\circ} \mathrm{C}$ while the coolant fluid temperature was kept constant at $15 \pm 1^{\circ} \mathrm{C}$. Feed and coolant flowrates were adjusted to $4 \mathrm{~L} \cdot \mathrm{min}^{-1}$. A total recycling of the concentrate and permeate towards the feed tank was performed in order to ensure a constant composition of the feed solution (volume reduction ratio VRR $=1$ ). 
125

126

127

129

130

131

132

133

134

135

136

137

138

139

140

141

142

143

144

145

146

147

148

AGMD separation performance was evaluated in terms of total permeate flux $(J)$, acid rejection $(R)$ and separation factor (SF).

The permeate flux $\left(J_{p}\right)$ can be defined as follows:

$$
J_{p}=\frac{\Delta m}{\Delta t * S}
$$

With:

- $\Delta \mathrm{m}$ the permeate mass collected $(\mathrm{kg})$

- $\Delta \mathrm{t}$ the sampling time (h)

- $\quad$ s the effective membrane surface $\left(\mathrm{m}^{2}\right)$

The permeate was sampled periodically and all measurements were performed in duplicate to calculate an average value. The precision on the permeate flux calculation was better than $5 \%$.

The rejection of carboxylic acids $\left(R_{i}\right)$ was calculated using equation 2. Retentate and permeate concentrations were determined by ion chromatography.

(1)

$R_{i}=1-\frac{C p_{i}}{C_{f i}}$

With:

- $\quad C p_{i}$ the concentration of compound $\mathrm{i}$ in the permeate $\left(\mathrm{g} \cdot \mathrm{L}^{-1}\right)$

- $\quad \mathrm{Cf}_{\mathrm{i}}$ the concentration of compound $\mathrm{i}$ in the feed $\left(\mathrm{g} \cdot \mathrm{L}^{-1}\right)$

Finally, the separation factor (eq. 3) was used to quantify the efficiency of the selective separation of two compounds $i$ and $j$.

$$
S F_{i / j}=\frac{C_{p, i} / C_{f, i}}{C_{p, j} / C_{f, j}}=\frac{1-R_{i}}{1-R_{j}}
$$

With: 
- SF the separation factor

- $\quad C_{p, i}$ and $C_{f, i}$ the concentration of compound $i\left(g \cdot L^{-1}\right)$ in the permeate and in the feed respectively - $\quad C_{p, j}$ and $C_{f, j}$ the concentration of compound $j\left(g . L^{-1}\right)$ in the permeate and in the feed respectively

\subsection{Determination of apparent energy activation}

In MD, the variation of the permeate fluxes with feed temperature might be modeled according to an Arrhenius-type equation enabling to determine the apparent energy of activation for molecule transfer through the membrane ( $\left.E_{a p p}\right)$ [37-39].

$$
J_{i}=J_{0, i} \exp \left(-\frac{E_{a p p, i}}{R T_{f}}\right)
$$

With:

- $\quad \mathrm{J}_{\mathrm{i}}$ the molar flux of compound i across the membrane $\left(\mathrm{mol} \cdot \mathrm{h}^{-1} \cdot \mathrm{m}^{-2}\right)$

- $\quad J_{0, i}$ is a pre-exponential factor for compound $\mathrm{i}\left(\mathrm{J}_{\mathrm{i}}\right.$ flux at infinite temperature) (mol. $\left.\mathrm{h}^{-1} \cdot \mathrm{m}^{-2}\right)$

- $\quad E_{a p p, i}$ is the apparent energy of activation of compound $i\left(J \cdot \mathrm{mol}^{-1}\right)$

- $\quad R$ is the universal gas constant $\left(8.314 \mathrm{~J} \cdot \mathrm{mol}^{-1} \cdot \mathrm{K}^{-1}\right)$

- $T_{f}$ is the absolute feed temperature (K)

Equation (4) can be linearized allowing the determination of the apparent energy of activation ( $\left.E_{\text {app }}\right)$ from the slope of equation (5).

$$
\operatorname{Ln}\left(U_{i}\right)=\operatorname{Ln}\left(J_{0, i}\right)-\frac{E_{a p p, i}}{R T_{f}}
$$

\subsection{Feed and permeate analysis}

Carboxylic acid quantification in the feed and permeate solutions was performed by ion chromatography. A Dionex DX120 system equipped with a Dionex AS11-HS (4×250 mm) column coupled to a conductivity detector was used. The injection volume was set at $250 \mu \mathrm{L}$ and the separation was performed using a mixture of potassium hydroxide $(\mathrm{KOH})$ and water as eluent. The operating 
conditions were as follow: 0-10 min (isocratic $10 \mathrm{mM}$ ); $10-25 \mathrm{~min}$ (gradient from 10 to $45 \mathrm{mM}$ ); $25-$ $35 \mathrm{~min}$ (isocratic $45 \mathrm{mM}$ ). The eluent flow rate was adjusted to $1 \mathrm{~mL} \mathrm{~min}^{-1}$.

HPLC was used to quantify the ethanol concentration in feed solution and permeate samples. A HPX$87 \mathrm{H}\left(300 \times 7.8 \mathrm{~mm}, \mathrm{BIO}-\mathrm{RAD}\right.$, Hercules, CA, USA) column was used. It was maintained at $45^{\circ} \mathrm{C}$ using an oven (Cro-Cir TM, Cluzeau Info-Labo, ste Foy La Grande, France) and fed using an isocratic pump (WATERS 510, Milford, MA, USA) with sulfuric acid $(0.01 \mathrm{~N})$ as eluent at a flow rate of $0.7 \mathrm{~mL} \cdot \mathrm{min}^{-1}$. Detection was performed by means of a refractometer (ERC 7512, Shimadzu).

\section{Results and discussion}

\subsection{Carboxylic acid rejection in AGMD}

\subsubsection{Influence of the carboxylic acid structure}

The influence of the carboxylic acid structure on AGMD performance was studied using binary carboxylic acid-water (10 g. $\mathrm{L}^{-1}$, natural pH) mixtures as the feed solutions. Figure 1 shows the evolution of both the permeate flux and the acid rejection for the three different carboxylic acids considered in this study. For these experiments, the feed temperature was set to $50 \pm 1^{\circ} \mathrm{C}$.

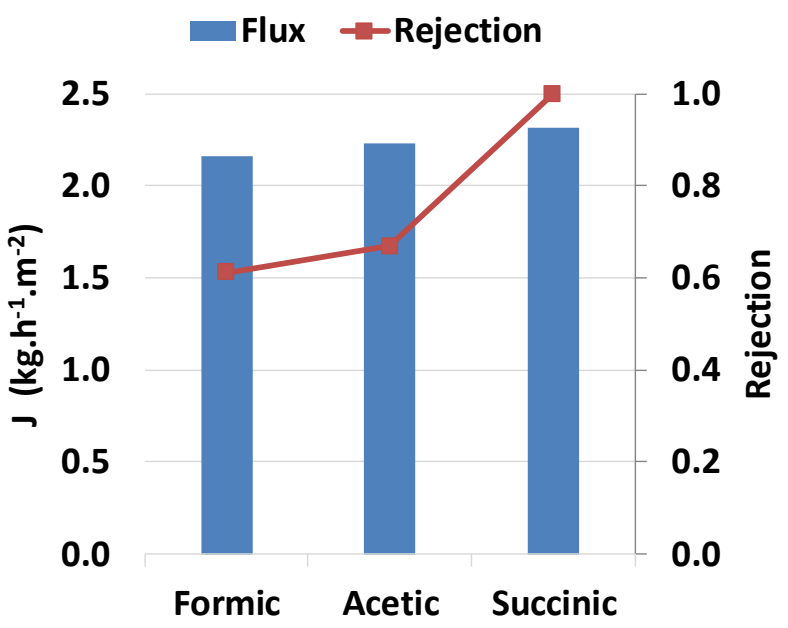

Figure 1: Influence of carboxylic acid structure on permeate flux and rejection $\left(10 \mathrm{~g} . \mathrm{L}^{-1}\right.$, natural $\mathrm{pH}$, $\mathrm{T}_{\text {feed }}=50^{\circ} \mathrm{C}, \mathrm{T}_{\text {coolant }}=15^{\circ} \mathrm{C}$, feed and coolant flowrates $4 \mathrm{~L} \cdot \mathrm{min}^{-1}$ ) 
The permeate flux values were similar $\left(2.2 \pm 0.1 \mathrm{~kg} \cdot \mathrm{h}^{-1} \cdot \mathrm{m}^{-2}\right)$ for the three carboxylic acid solutions

195 indicating that, in the tested conditions, the acid structure as no impact on the permeate flux. The insensitivity of the permeate flux to the feed composition has previously been observed in different studies dealing with the MD of dilute aqueous solutions containing low amount of volatile solutes $[14,22]$. This might be explained by the low amount of acid in the feed and permeate solutions. Thus, in the present conditions, the permeate was mostly composed of water causing the total permeate flux to be insensitive to the acid structure.

On the other hand, acid rejection was highly dependent on the acid structure. Thus, formic and acetic acids were partially rejected by the membrane while full-rejection was observed for succinic acid. Furthermore, formic acid was less rejected by the membrane than acetic acid. These results were in good accordance with the respective volatility of the different acids as formic acid was the most volatile molecule while succinic acid was the less volatile one (Table 1). In addition, it is interesting to note that formic and succinic acids had different transfer behaviors despite having close values of logP (but different vapor pressure and boiling points). This revealed that, in the tested conditions, acid volatilities seemed to play a greater role on molecule transfer trough the membrane compared to their hydrophilic/hydrophobic features.

\subsubsection{Influence of the feed temperature}

212 The influence of the feed temperature $\left(37-60^{\circ} \mathrm{C}\right)$ on separation performance was studied using binary 213 acid-water solutions ( $10 \mathrm{~g}^{\mathrm{L}} \mathrm{L}^{-1}$, natural $\left.\mathrm{pH}\right)$. Figure 2 shows the evolution of both the permeate flux and the acid retention for the three carboxylic acids. 

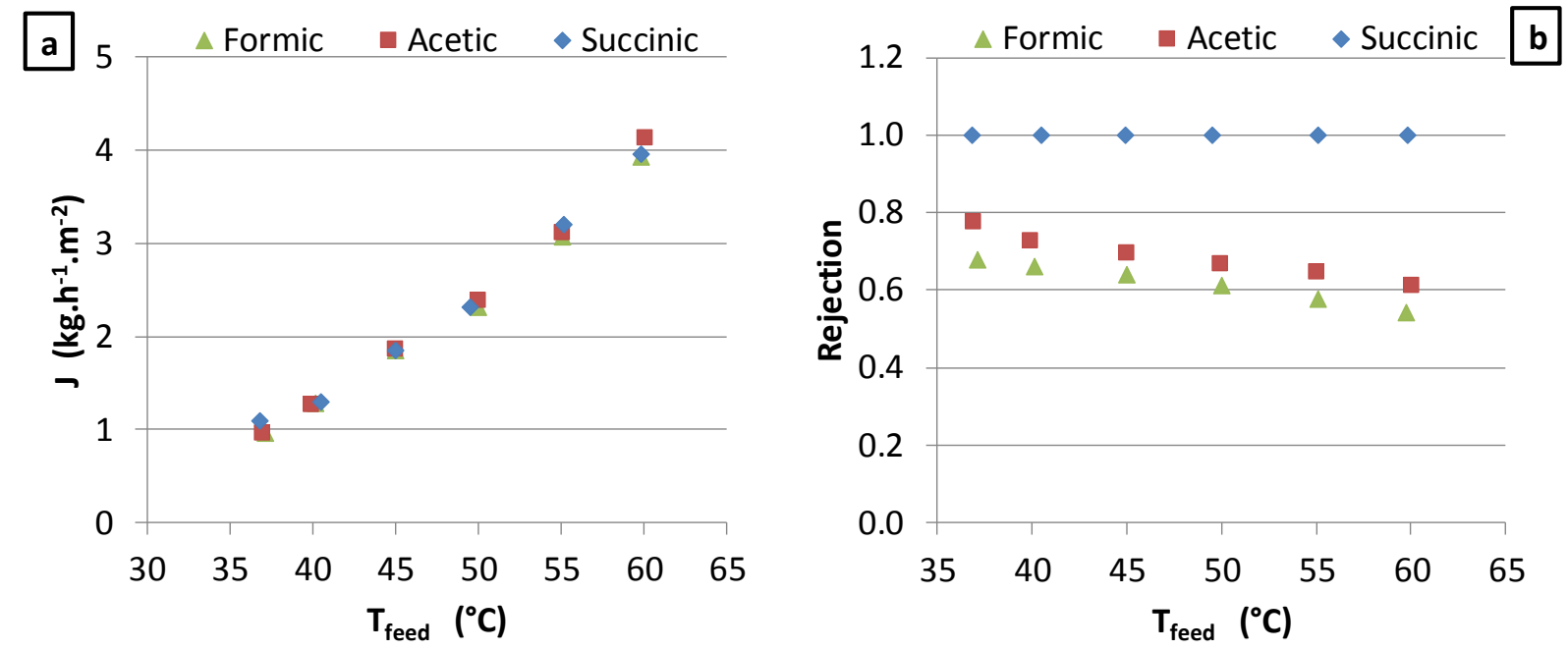

Figure 2: Influence of the feed temperature on the permeate flux (a) and acid rejection (b) (binary acid-water solution at $10 \mathrm{~g} . \mathrm{L}^{-1}$, natural $\mathrm{pH}, \mathrm{T}_{\text {coolant }}=15^{\circ} \mathrm{C}$, feed and coolant flowrates $4 \mathrm{~L} \cdot \mathrm{min}^{-1}$ )

Figure $2 \mathrm{a}$ shows the variation of the permeate flux according to the feed temperature. The well-known increase of the permeate flux with the feed temperature was observed. It was explained by the vapor pressure difference (which is the separation driving force) increase with the feed temperature according to Antoine's law [27]. Thus, for a constant temperature of coolant fluid, the separation driving force increases with the feed temperature thus leading to an increased permeate flux. Furthermore, as observed previously, the acid nature had no influence on the permeate flux, whatever the feed temperature. As explained before, this was be due the low amount of acid in both the feed and permeate fluids $[14,22]$. Whatever the acid nature, the minimum permeate flux value was $1.0 \mathrm{~kg} \cdot \mathrm{h}^{-}$ ${ }^{1} \cdot \mathrm{m}^{-2}$ at $37^{\circ} \mathrm{C}$ while a maximum permeate flux of roughly $4.0 \mathrm{~kg} \cdot \mathrm{h}^{-1} \cdot \mathrm{m}^{-2}$ was reached at a feed temperature of $60^{\circ} \mathrm{C}$.

When looking at the acid rejection (Figure $2 \mathrm{~b}$ ), the impact of the feed temperature depended on the acid structure. Thus, a constant and full rejection was observed for the succinic acid. However, formic and acetic acids rejections were found to be dependent on the feed temperature. In the present conditions, acetic acid rejection decreased from 0.78 to 0.61 while formic acid rejection varied from 
acetic acid rejection was higher than that of formic acid rejection whatever the feed temperature, in

236 good accordance with the molecule volatilities.

237 In order to get more insights into the variation of the acids rejection with the feed temperature, the natural logarithm of the molar fluxes of water and carboxylic acids through the membrane was plotted against the reciprocal temperature (Figure 3). It was thus possible to calculate, for each compound, the apparent energy barrier of transport through the membrane using the linearized Arrhenius equation (Eq. 5). Note that, for the sake of clarity, only one curve is displayed for the water flux as it was found to be similar for the three experiments with the three different carboxylic acids. Succinic acid was also excluded as full rejection was observed whatever the feed temperature.

From figure 3, it can be observed that the variation of the natural logarithm of the water flux with the reciprocal temperature was linear. This indicated that the water transport through the membrane followed an Arrhenius-type law and thus was a temperature-activated process. The same observation

247 was made for the formic and acetic acids. Apparent energies of activation could be calculated, for each

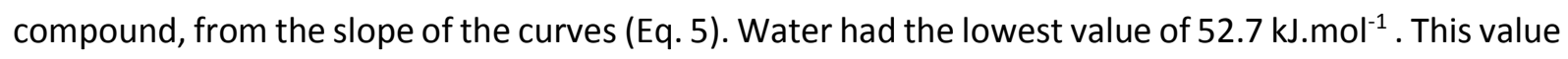
was found to be of the same order of magnitude compared to others calculated in previous studies dedicated to AGMD [39]. Apparent energies of activation was 62.6 and $67.2 \mathrm{~kJ} \cdot \mathrm{mol}^{-1}$ for the formic and

251 acetic acids respectively. A higher apparent energy activation indicates a higher sensitivity to 252 temperature (Eq. 4). In other words, for a given increase of feed temperature, the transmembrane flux 253 increase was greater for the carboxylic acids than for water flux. Accordingly, when the temperature 254 was increased, an increased acid concentration in the permeate occurred causing an acid rejection 255 drop (Figure 2b). 


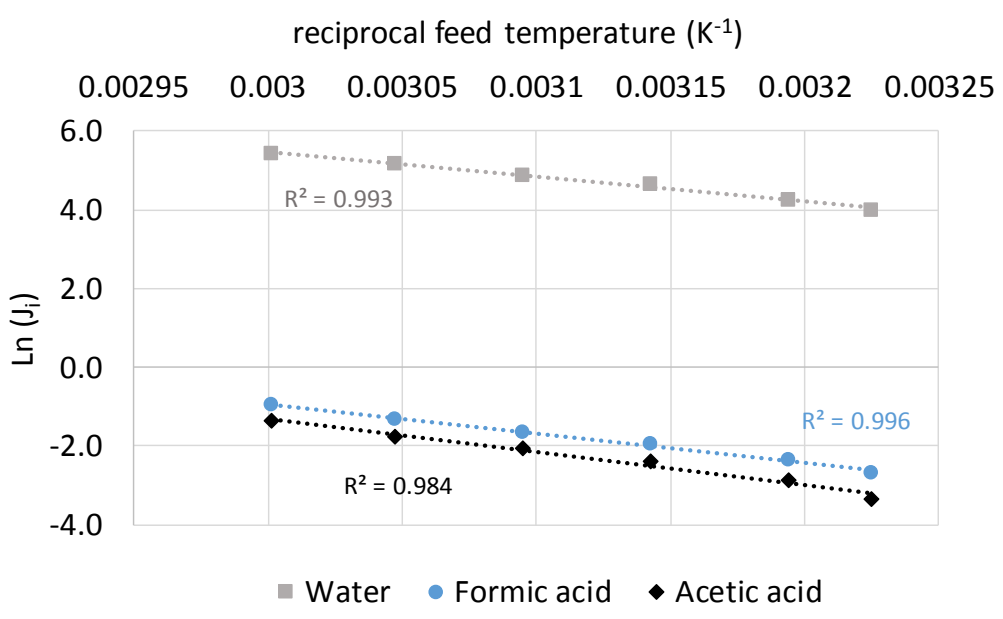

Water * Formic acid * Acetic acid

257 Figure 3: Variation of molar fluxes of the different compounds through the membrane against the 258 reciprocal feed temperature (binary acid-water solution at $10 \mathrm{~g} \cdot \mathrm{L}^{-1}$, natural $\mathrm{pH}, \mathrm{T}_{\text {coolant }}=15^{\circ} \mathrm{C}$, feed and coolant flowrates 4 L. $\mathrm{min}^{-1}$ )

\subsubsection{Influence of the acid concentration}

The influence of the acid concentration (5-30 g. $\mathrm{L}^{-1}$, natural $\mathrm{pH}$ ) on the permeate flux, at different feed temperatures, is shown in figure 4a for binary carboxylic acid-water mixtures. Succinic acid was not considered as full retention was observed for all previous tested operating conditions. 

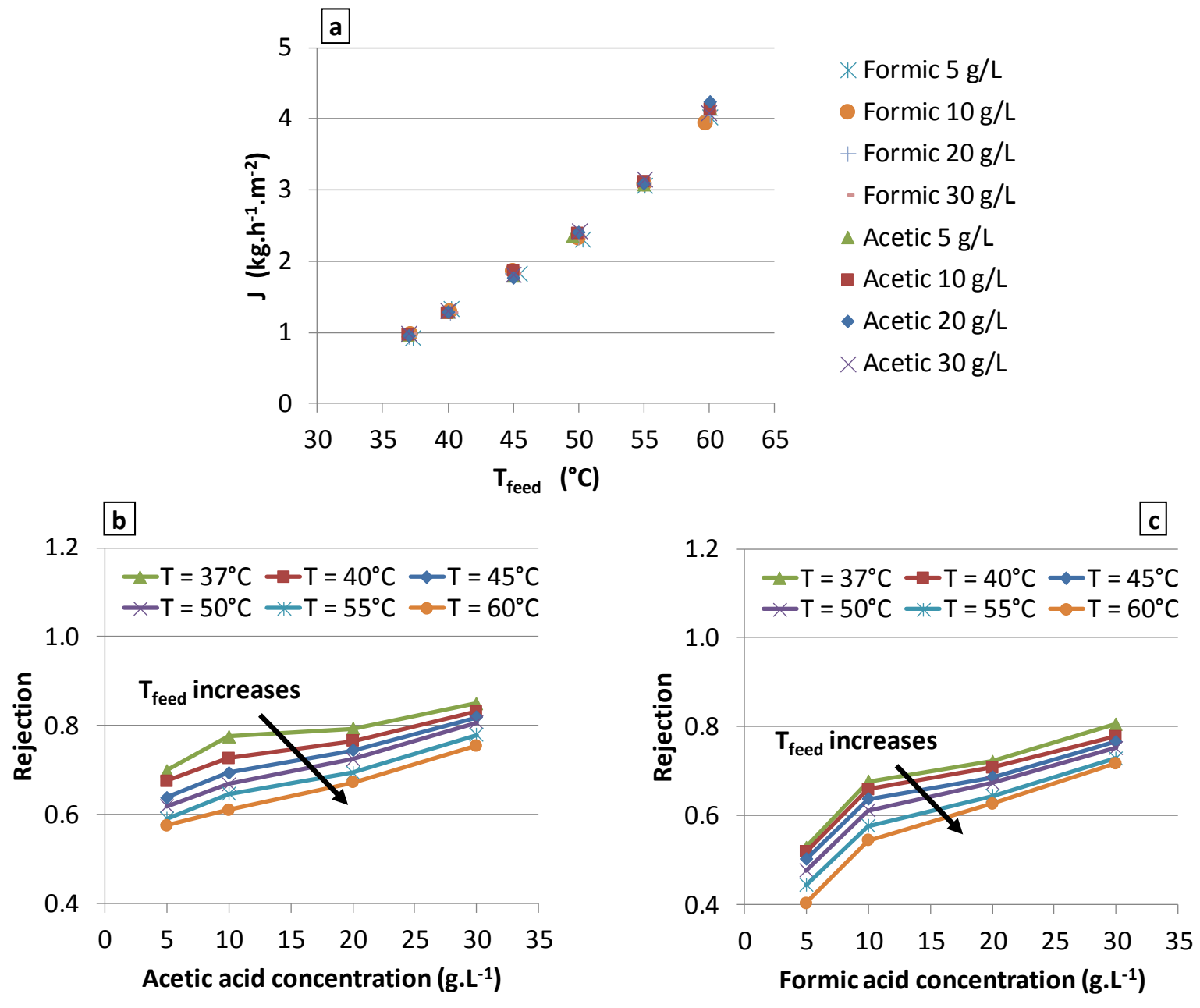

Figure 4: Influence of the acid concentration on (a) the permeate flux, (b) the acetic acid rejection and (c) the formic acid rejection (binary acid-water solutions, natural $\mathrm{pH}, \mathrm{T}_{\text {coolant }}=15^{\circ} \mathrm{C}$, feed and coolant flowrates 4 L. $\min ^{-1}$ )

Again, it was found that the permeate flux increased with temperature while it was insensitive to the feed solution composition (i.e. acid concentration). Furthermore, whatever the acid concentration, the rejection decreased when the feed temperature increased (as shown for $10 \mathrm{~g} / \mathrm{L}$ in the previous section). On the other hand, whatever the feed temperature, acid rejection was shown to increase with the acid concentration (Figure $4 \mathrm{~b}$ and $4 \mathrm{c}$ ). Carboxylic acids form dimers in the gas phase and in aqueous solutions as a result of both hydrogen bonding $(\mathrm{C}=\mathrm{O}---\mathrm{H}-\mathrm{O})$ and hydrophobic interactions 
277 (molecule $1+$ molecule $2 \leftrightarrow$ dimer) and the reported experimental values of $p K_{D}\left(=-\log K_{D}\right.$, with $K_{D}$ the 278 dimerization thermodynamic constant) in the range $0.73-1.45$ for acetic acid at $25^{\circ} \mathrm{C}$ [41], it comes that the concentration of acetic acid dimers is roughly proportional to the square of the acetic acid concentration introduced in the system (the same is true for formic acid dimers for which $p K_{D}$ was reported in the range $1.24-2.08$ at $25^{\circ} \mathrm{C}$ [41]). It is therefore hypothesized that the increase in the rejection of both formic and acetic acids with concentration results from the more significant formation of dimers as the concentration increases.

This point is interesting as it is contrary to what is classically observed for pressure-driven processes (which are alternative membrane techniques that can be used for carboxylic acid separation from water $[42,43])$ for which solute rejection tends to decrease with increasing solute concentration due to concentration polarization (and surface charge screening effects in the case of charged solutes). It is also worth noting that the absence of rejection decrease with increasing feed concentrations has previously been reported in MD for water-ethanol mixtures [14].

The present results thus suggested that AGMD might be a suitable alternative to pressure-driven processes for the concentration/separation of carboxylic acids.

\subsubsection{Influence of the $\mathrm{pH}$ of the feed solution}

In order to evaluate the influence of the acid dissociation rates on their rejection, the influence of the $\mathrm{pH}$ of the feed solution was studied both for the formic and acetic acids $\left(5 \mathrm{~g}^{\mathrm{L}} \mathrm{L}^{-1}\right)$. For each acid, a set of experiments were performed for which the adjustment of the $\mathrm{pH}$ of the feed solution allowed to reach different dissociation rates.

Figure 5a shows the relative distribution of both the acetic acid and acetate ion according to the $\mathrm{pH}$ of the solution. The pKa of acetic acid varies from 4.76 to 4.81 with temperature increasing from $25^{\circ} \mathrm{C}$ to $60^{\circ} \mathrm{C}[44]$ and thus can be considered constant in the temperature range investigated in this study. Accordingly, three different solutions at pH equal to $2.8(\approx 100 \% \mathrm{R}-\mathrm{COOH}), 4.8(50 / 50 \% \mathrm{R}-\mathrm{COOH} / \mathrm{R}-$ $\left.\mathrm{COO}^{-}\right)$and $7.0\left(\approx 100 \% \mathrm{R}^{\left.-\mathrm{COO}^{\circ}\right)}\right.$ were considered. The rejection rates $\left(\mathrm{T}_{\text {feed }}=60^{\circ} \mathrm{C}\right)$ obtained for the 
302 different feed solutions are shown on figure $5 \mathrm{~b}$. The rejection rate was found to vary with the $\mathrm{pH}$ of

303 the feed solution. The lowest rejection rate was observed at $\mathrm{pH} 2.8(<0.6)$ while the maximum

304 rejection rate (99.8) was observed at $\mathrm{pH}$ 7. These results thus revealed the increase of the rejection

305 rate with the acetic acid dissociation rate: the higher the relative amount of acetate ions, the higher

306 the rejection rate. From a thermodynamic point of view, this result can be explained by the fact that

307 ions can not be vaporized in the present conditions.

308 The pKa of formic acid varies from 3.75 to 3.81 with temperature increasing from $25^{\circ} \mathrm{C}$ to $60^{\circ} \mathrm{C}$ [45] .

309 Considering formic acid-water binary mixtures of $\mathrm{pH} 2.2,3.7$ and 7.3 the same behavior as for acetic

310 acid was observed (Figures $5 \mathrm{c}$ and $5 \mathrm{~d}$ ).

311

312 

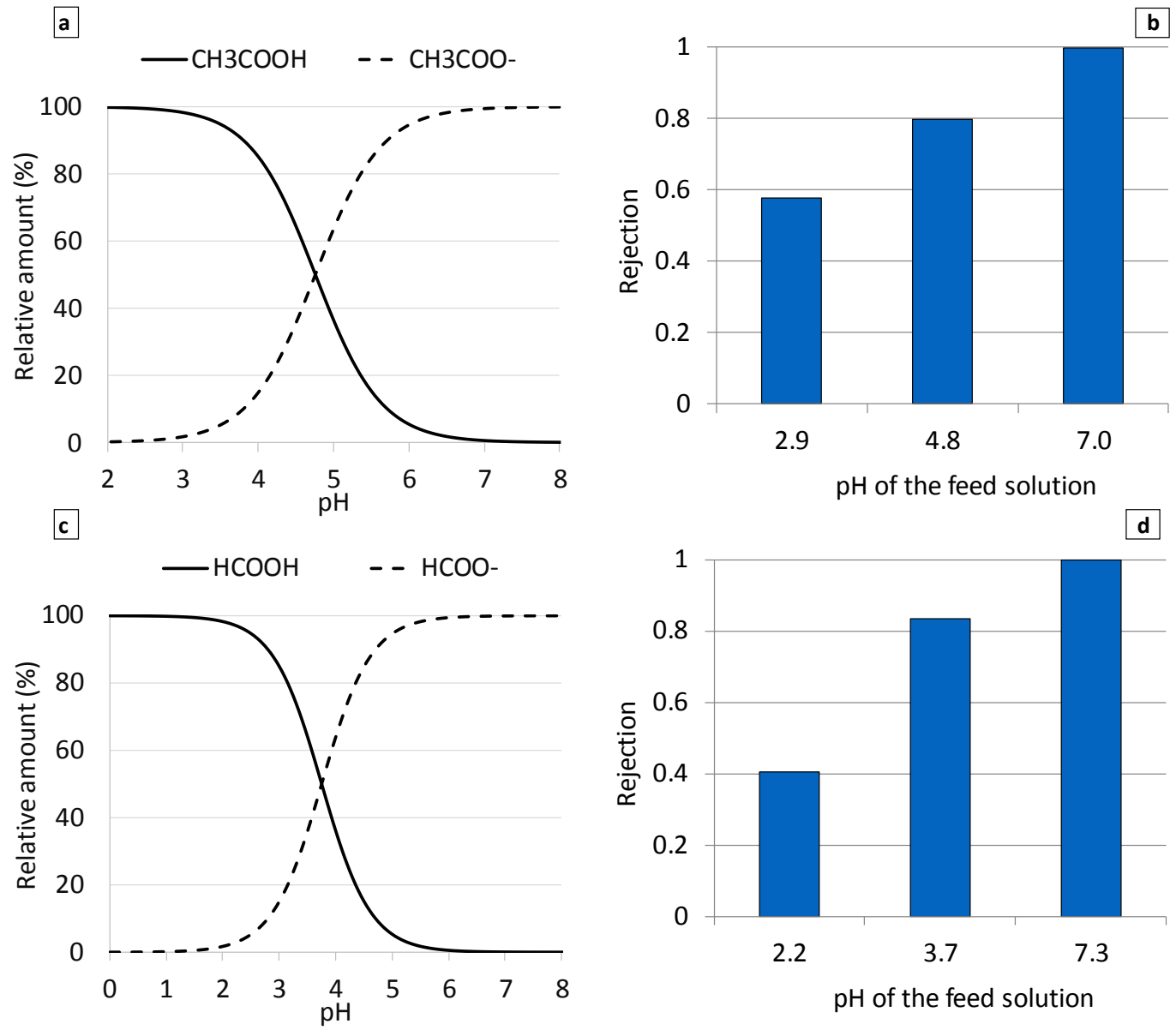

Figure 5: Dissociation rate of acetic acid according to $\mathrm{pH}(\mathrm{a})$, influence of the feed solution $\mathrm{pH}$ on the acetic acid rejection (b) dissociation rate of formic acid according to $\mathrm{pH}(\mathrm{c})$ and influence of the feed solution $\mathrm{pH}$ on the formic acid rejection (d) (binary carboxylic acid-water solutions $5 \mathrm{~g} \cdot \mathrm{L}^{-1}, \mathrm{~T}_{\text {feed }}=60^{\circ} \mathrm{C}$, $\mathrm{T}_{\text {coolant }}=15^{\circ} \mathrm{C}$, feed and coolant flowrates $4 \mathrm{~L} \cdot \mathrm{min}^{-1}$ )

\subsection{Implications for selective separation of ethanol-acetic acid aqueous mixtures}

321 The production of bioethanol by yeast fermentation usually leads to complex aqueous mixtures

322 containing ethanol and acetic acid, a by-product of the bioreaction [46-49]. MD has previously been

323 demonstrated to be a suitable technique to extract ethanol the fermentation broths. The permeate

324 obtained is thus an aqueous mixture with enriched ethanol content compared to the feed solution.

325 However, acetic acid might also be found in the permeate thus requiring extra purification steps $[46,47,50]$. Taking part of the knowledge obtained from the parametric study presented above, the 
a

$$
\mathbf{p H}=\mathbf{3}
$$

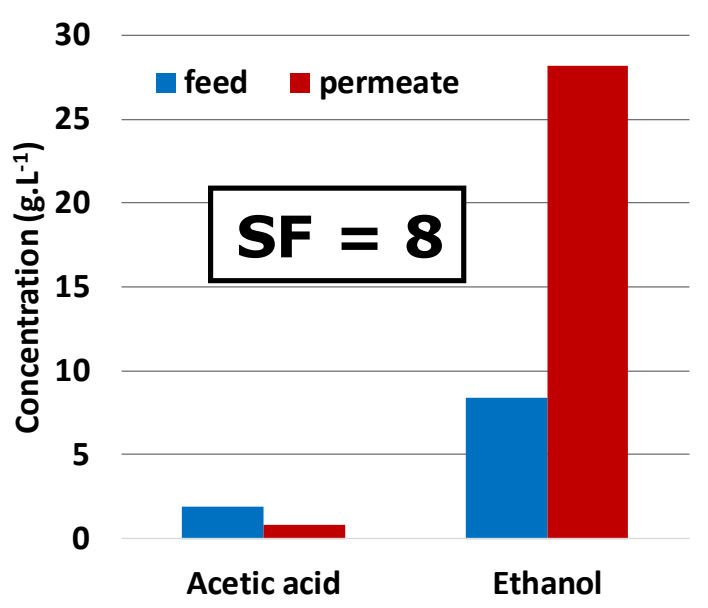

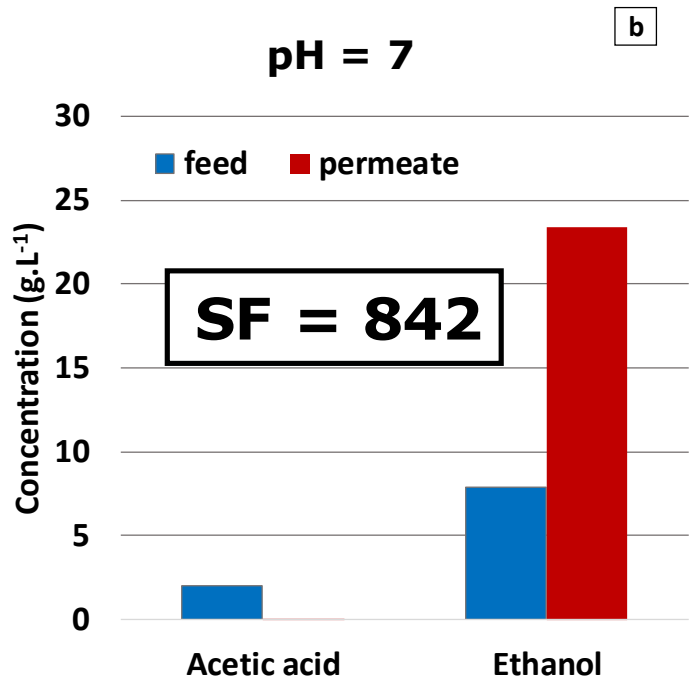

Figure 6: Acetic acid and ethanol concentrations in the feed and permeate solutions during the AGMD of water - ethanol (8 g. $\left.\mathrm{L}^{-1}\right)-$ acetic acid mixtures $\left(2 \mathrm{~g} . \mathrm{L}^{-1}\right)$ at $\mathrm{pH} 3(\mathrm{a})$ and 7 (b) $\left(\mathrm{T}_{\text {feed }}=60^{\circ} \mathrm{C}\right.$, $\mathrm{T}_{\text {coolant }}=15^{\circ} \mathrm{C}$, feed and coolant flowrates 4 L. $\mathrm{min}^{-1}$ )

At $\mathrm{pH} 3$ and 7 , an increase of the ethanol concentration in the permeate was observed compared to the feed meaning that the ethanol was successfully extracted from the feed solution. On the other hand, at $\mathrm{pH} 3$ a partial transmission of acetic acid through the membrane was observed leading to a rejection rate of $56 \%$. Interestingly, at $\mathrm{pH} 7$, the almost full rejection of the acetic acid was observed (99.6\%) and a negligible concentration of acetic acid was detected in the permeate solution $(<0.01$ g.L$\left.343{ }^{1}\right)$. 
The results obtained here indicated that the feed solution properties play a key role towards the selectivity of the separation. In addition, it was underlined that a simple adjustment of the feed chemistry is a possible technique to favor the selective separation of the ethanol from acetic acid by MD. Thus, by adjusting the $\mathrm{pH}$ of the solution to 7 , it was possible to increase the ethanol/acetic acid separation factor by 2 orders of magnitude (from 8 to 842 ) compared to that of $\mathrm{pH} 3$.

It was here demonstrated that the physicochemistry of the feed solution plays a key role on AGMD separation performance. The results obtained thus underlined that, when MD is used as a downstream unit operation following a (bio)reactor, it is necessary to take into consideration the separation technique specifications when designing the (bio)production step. Thus, depending on the operating conditions during the (bio)reaction, the physicochemical properties of the obtained mixture might vary a lot and thus drastically impact the separation efficiency. It is thus desirable to perform the joint optimization of the coupled (bio)production/separation steps instead of the individual optimization of each steps.

\section{Conclusion}

The behavior of volatile compounds in MD is poorly understood. In this context, this study aimed at investigate the rejection efficiency of MD towards carboxylic acids (formic, acetic and succinic acids) under different operating conditions.

In the tested conditions, it was demonstrated that the permeate flux increased with the feed temperature but was insensitive to the other studied parameters (acid type, acid concentration, $\mathrm{pH}$ of the feed solution). On the other hand, acid rejection was found to be highly dependent of the carboxylic acid structure (the more volatile acid being the less retained by the membrane). It was also found that the acid rejection increased with the acid dissociation rate as well as with its concentration in the feed solution. This MD feature is interesting as the opposite phenomenon is usually observed

367 for pressure-driven membrane processes due to polarization concentration (and possible surface charge screening). 
Finally, it was demonstrated how it can be taken advantage of the understanding of the behavior of acetic acid in MD to successfully achieve selective separation of ethanol from an acetic acid/ethanol aqueous mixture by a simple feed solution $\mathrm{pH}$ adjustment in the typical case of the extraction of bioethanol from a fermentation broth.

373

374

\section{Acknowledgements:}

Dr. Hayet Djelal is acknowledged for the ethanol concentration determination by HPLC analyses performed at Unilasalle-EME. A. Khiter acknowledges the « Ministère de l'enseignement supérieure et de la recherche scientifique Algérienne, direction de la coopération et des échanges interuniversitaires » for funding (Grant 378/PNE/FRANCE/2016/2017).

\section{References}

[1] A. Ali, R.A. Tufa, F. Macedonio, E. Curcio, E. Drioli, Membrane technology in renewable-energydriven desalination, Renew. Sustain. Energy Rev. 81 (2018) 1-21. https://doi.org/10.1016/j.rser.2017.07.047.

[2] G. Gopi, G. Arthanareeswaran, A. Ismail, Perspective of renewable desalination by using membrane distillation, Chem. Eng. Res. Des. 144 (2019) 520-537. https://doi.org/10.1016/j.cherd.2019.02.036.

[3] P. Byrne, L. Fournaison, A. Delahaye, Y. Ait Oumeziane, L. Serres, P. Loulergue, A. Szymczyk, D. Mugnier, J.-L. Malaval, R. Bourdais, H. Gueguen, O. Sow, J. Orfi, T. Mare, A review on the coupling of cooling, desalination and solar photovoltaic systems, Renew. Sustain. Energy Rev. 47 (2015) 703-717. https://doi.org/10.1016/j.rser.2015.03.083.

[4] A.T. Diaby, P. Byrne, P. Loulergue, B. Balannec, A. Szymczyk, T. Maré, O. Sow, Design study of the coupling of an air gap membrane distillation unit to an air conditioner, Desalination. 420 (2017) 308-317. https://doi.org/10.1016/j.desal.2017.08.001. 
[5] N. Thomas, M.O. Mavukkandy, S. Loutatidou, H.A. Arafat, Membrane distillation research \& implementation: Lessons from the past five decades, Sep. Purif. Technol. 189 (2017) 108-127. https://doi.org/10.1016/j.seppur.2017.07.069.

[6] T.Y. Cath, D. Adams, A.E. Childress, Membrane contactor processes for wastewater reclamation in space: II. Combined direct osmosis, osmotic distillation, and membrane distillation for treatment of metabolic wastewater, J. Membr. Sci. 257 (2005) 111-119. https://doi.org/10.1016/j.memsci.2004.07.039.

[7] A. Criscuoli, J. Zhong, A. Figoli, M.C. Carnevale, R. Huang, E. Drioli, Treatment of dye solutions by vacuum membrane distillation, Water Res. 42 (2008) 5031-5037. https://doi.org/10.1016/j.watres.2008.09.014.

[8] P. Loulergue, J. Mendret, G. Lesage, B. Teychene, Chapter 9 - Membrane processes for wastewater remediation, in: A. Figoli, Y. Li, A. Basile (Eds.), Curr. Trends Future Dev. BioMembr., Elsevier, 2020: pp. 175-211. https://doi.org/10.1016/B978-0-12-816778-6.00009-6.

[9] S. Nene, S. Kaur, K. Sumod, B. Joshi, K.S.M.S. Raghavarao, Membrane distillation for the concentration of raw cane-sugar syrup and membrane clarified sugarcane juice, Desalination. 147 (2002) 157-160. https://doi.org/10.1016/S0011-9164(02)00604-5.

[10] V.D. Alves, I.M. Coelhoso, Orange juice concentration by osmotic evaporation and membrane distillation: A comparative study, J. Food Eng. 74 (2006) 125-133. https://doi.org/10.1016/j.jfoodeng.2005.02.019.

[11] S. Gunko, S. Verbych, M. Bryk, N. Hilal, Concentration of apple juice using direct contact membrane distillation, Desalination. 190 (2006) 117-124. https://doi.org/10.1016/j.desal.2005.09.001.

[12] G. Lewandowicz, W. Białas, B. Marczewski, D. Szymanowska, Application of membrane distillation for ethanol recovery during fuel ethanol production, J. Membr. Sci. 375 (2011) 212219. https://doi.org/10.1016/j.memsci.2011.03.045. 
[13] M. Tomaszewska, L. Białończyk, Production of ethanol from lactose in a bioreactor integrated with membrane distillation, Desalination. 323 (2013) 114-119. https://doi.org/10.1016/j.desal.2013.01.026.

[14] P. Loulergue, B. Balannec, L. Fouchard-Le Graët, A. Cabrol, W. Sayed, H. Djelal, A. Amrane, A. Szymczyk, Air-gap membrane distillation for the separation of bioethanol from algal-based fermentation broth, Sep. Purif. Technol. 213 (2019) 255-263. https://doi.org/10.1016/j.seppur.2018.12.047.

[15] Z. Xie, T. Duong, M. Hoang, C. Nguyen, B. Bolto, Ammonia removal by sweep gas membrane distillation, Water Res. 43 (2009) 1693-1699. https://doi.org/10.1016/j.watres.2008.12.052.

[16] C.A. Quist-Jensen, J.M. Sørensen, A. Svenstrup, L. Scarpa, T.S. Carlsen, H.C. Jensen, L. Wybrandt, M.L. Christensen, Membrane crystallization for phosphorus recovery and ammonia stripping from reject water from sludge dewatering process, Desalination. 440 (2018) 156-160. https://doi.org/10.1016/j.desal.2017.11.034.

[17] K.A. Salls, D. Won, E.P. Kolodziej, A.E. Childress, S.R. Hiibel, Evaluation of semi-volatile contaminant transport in a novel, gas-tight direct contact membrane distillation system, Desalination. 427 (2018) 35-41. https://doi.org/10.1016/j.desal.2017.11.001.

[18] M. Yao, Y.C. Woo, J. Ren, L.D. Tijing, J.-S. Choi, S.-H. Kim, H.K. Shon, Volatile fatty acids and biogas recovery using thermophilic anaerobic membrane distillation bioreactor for wastewater reclamation, J. Environ. Manage. 231 (2019) 833-842.

https://doi.org/10.1016/j.jenvman.2018.11.009.

[19] K.C. Wijekoon, F.I. Hai, J. Kang, W.E. Price, T.Y. Cath, L.D. Nghiem, Rejection and fate of trace organic compounds (TrOCs) during membrane distillation, J. Membr. Sci. 453 (2014) 636-642. https://doi.org/10.1016/j.memsci.2013.12.002.

[20] J.M. Winglee, N. Bossa, D. Rosen, J.T. Vardner, M.R. Wiesner, Modeling the Concentration of Volatile and Semivolatile Contaminants in Direct Contact Membrane Distillation (DCMD) 
Product Water, Environ. Sci. Technol. 51 (2017) 13113-13121.

https://doi.org/10.1021/acs.est.6b05663.

[21] M. Yao, Y.C. Woo, L.D. Tijing, J.-S. Choi, H.K. Shon, Effects of volatile organic compounds on water recovery from produced water via vacuum membrane distillation, Desalination. 440 (2018) 146-155. https://doi.org/10.1016/j.desal.2017.11.012.

[22] M.C. García-Payo, M.A. Izquierdo-Gil, C. Fernández-Pineda, Air gap membrane distillation of aqueous alcohol solutions, J. Membr. Sci. 169 (2000) 61-80. https://doi.org/10.1016/S03767388(99)00326-9.

[23] A. Kujawska, J.K. Kujawski, M. Bryjak, M. Cichosz, W. Kujawski, Removal of volatile organic compounds from aqueous solutions applying thermally driven membrane processes. 2. Air gap membrane distillation, J. Membr. Sci. 499 (2016) 245-256. https://doi.org/10.1016/j.memsci.2015.10.047.

[24] F.A. Banat, J. Simandl, Membrane distillation for dilute ethanol: Separation from aqueous streams, J. Membr. Sci. 163 (1999) 333-348. https://doi.org/10.1016/S0376-7388(99)00178-7.

[25] D. Won, Treatment Performance of Direct Contact Membrane Distillation for Volatile, Semi-, (n.d.) 55 .

[26] X. Yang, H. Pang, J. Zhang, A. Liubinas, M. Duke, Sustainable waste water deammonification by vacuum membrane distillation without $\mathrm{pH}$ adjustment: Role of water chemistry, Chem. Eng. J. 328 (2017) 884-893. https://doi.org/10.1016/j.cej.2017.07.104.

[27] A. Alkhudhiri, N. Darwish, N. Hilal, Membrane distillation: A comprehensive review, Desalination. 287 (2012) 2-18. https://doi.org/10.1016/j.desal.2011.08.027.

[28] H. Song, S.Y. Lee, Production of succinic acid by bacterial fermentation, Enzyme Microb. Technol. 39 (2006) 352-361. https://doi.org/10.1016/j.enzmictec.2005.11.043.

[29] C. Wang, W. Ming, D. Yan, C. Zhang, M. Yang, Y. Liu, Y. Zhang, B. Guo, Y. Wan, J. Xing, Novel membrane-based biotechnological alternative process for succinic acid production and 
chemical synthesis of bio-based poly (butylene succinate), Bioresour. Technol. 156 (2014) 6-13. https://doi.org/10.1016/j.biortech.2013.12.043.

[30] A. Álvarez, A. Bansode, A. Urakawa, A.V. Bavykina, T.A. Wezendonk, M. Makkee, J. Gascon, F. Kapteijn, Challenges in the Greener Production of Formates/Formic Acid, Methanol, and DME by Heterogeneously Catalyzed CO2 Hydrogenation Processes, Chem. Rev. 117 (2017) 98049838. https://doi.org/10.1021/acs.chemrev.6b00816.

[31] A.-P. Zeng, New bioproduction systems for chemicals and fuels: Needs and new development, Biotechnol. Adv. 37 (2019) 508-518. https://doi.org/10.1016/j.biotechadv.2019.01.003.

[32] PubChem, Formic acid, (n.d.). https://pubchem.ncbi.nlm.nih.gov/compound/284 (accessed March 27, 2020).

[33] PubChem, Acetic acid, (n.d.). https://pubchem.ncbi.nlm.nih.gov/compound/176 (accessed March 27, 2020).

[34] PubChem, Succinic acid, (n.d.). https://pubchem.ncbi.nlm.nih.gov/compound/1110 (accessed March 27, 2020).

[35] PubChem, Ethanol, (n.d.). https://pubchem.ncbi.nlm.nih.gov/compound/702 (accessed March $27,2020)$.

[36] PubChem, Water, (n.d.). https://pubchem.ncbi.nlm.nih.gov/compound/962 (accessed March $27,2020)$.

[37] P. Peng, A.G. Fane, X. Li, Desalination by membrane distillation adopting a hydrophilic membrane, Desalination. 173 (2005) 45-54. https://doi.org/10.1016/j.desal.2004.06.208.

[38] J.I. Mengual, M. Khayet, M.P. Godino, Heat and mass transfer in vacuum membrane distillation, Int. J. Heat Mass Transf. 47 (2004) 865-875. https://doi.org/10.1016/j.ijheatmasstransfer.2002.09.001.

[39] J. Kujawa, W. Kujawski, Driving force and activation energy in air-gap membrane distillation process, Chem. Pap. 69 (2015) 1438-1444. https://doi.org/10.1515/chempap-2015-0155. 
[40] J. Chen, C.L. Brooks, H.A. Scheraga, Revisiting the Carboxylic Acid Dimers in Aqueous Solution: Interplay of Hydrogen Bonding, Hydrophobic Interactions, and Entropy, J. Phys. Chem. B. 112 (2008) 242-249. https://doi.org/10.1021/jp074355h.

[41] E.E. Schrier, Marcia. Pottle, H.A. Scheraga, The Influence of Hydrogen and Hydrophobic Bonds on the Stability of the Carboxylic Acid Dimers in Aqueous Solution, J. Am. Chem. Soc. 86 (1964) 3444-3449. https://doi.org/10.1021/ja01071a009.

[42] I.S. Han, M. Cheryan, Nanofiltration of model acetate solutions, J. Membr. Sci. 107 (1995) 107113. https://doi.org/10.1016/0376-7388(95)00107-N.

[43] S.H. Kang, Y.K. Chang, Removal of organic acid salts from simulated fermentation broth containing succinate by nanofiltration, J. Membr. Sci. 246 (2005) 49-57. https://doi.org/10.1016/j.memsci.2004.08.014.

[44] H.S. Harned, R.W. Ehlers, The Dissociation Constant of Acetic Acid from 0 to $60^{\circ}$ Centigrade1, J. Am. Chem. Soc. 55 (1933) 652-656. https://doi.org/10.1021/ja01329a027.

[45] H.S. Harned, N.D. Embree, The Ionization Constant of Formic Acid from 0 to $60^{\circ} 1$, J. Am. Chem. Soc. 56 (1934) 1042-1044. https://doi.org/10.1021/ja01320a010.

[46] M. Gryta, M. Barancewicz, Separation of volatile compounds from fermentation broth by membrane distillation, Pol. J. Chem. Technol. 13 (2011) 56-60. https://doi.org/10.2478/v10026-011-0038-1.

[47] M. Gryta, A. Markowska-Szczupak, J. Bastrzyk, W. Tomczak, The study of membrane distillation used for separation of fermenting glycerol solutions, J. Membr. Sci. 431 (2013) 1-8. https://doi.org/10.1016/j.memsci.2012.12.032.

[48] S. Fan, Z. Xiao, X. Tang, C. Chen, Y. Zhang, Q. Deng, P. Yao, W. Li, Inhibition effect of secondary metabolites accumulated in a pervaporation membrane bioreactor on ethanol fermentation of Saccharomyces cerevisiae, Bioresour. Technol. 162 (2014) 8-13. https://doi.org/10.1016/j.biortech.2014.03.140. 
518 [49] W. Sayed, A. Cabrol, R. Abdallah, S. Taha, A. Amrane, H. Djelal, Enhancement of ethanol

519 production from synthetic medium model of hydrolysate of macroalgae, Renew. Energy.

520 (2017). https://doi.org/10.1016/j.renene.2017.10.094.

521 [50] M. Gryta, The fermentation process integrated with membrane distillation, Sep. Purif. Technol.

522 24 (2001) 283-296. https://doi.org/10.1016/S1383-5866(01)00132-0.

523 